Arq. Bras. Med. Vet. Zootec., v.69, n.5, p.1203-1205, 2017

\title{
Peritonite encapsulante esclerosante em cão (Canis familiaris): relato de caso
}

\author{
[Sclerosing encapsulating peritonitis in dog (Canis familiaris): case report] \\ A.S.O. Santos, L.S. Lemos, M.A.D. Viestel, A.B.F. Rodrigues, \\ L.G. Almeida, E.C.Q. Carvalho \\ Universidade Estadual do Norte Fluminense Darcy Ribeiro - UENF - Campus dos Goytacazes, RJ
}

\section{RESUMO}

Um cão SRD, com cinco anos e histórico de ascite de evolução lenta com estruturas palpáveis foi submetido a exames clínicos, os quais foram inconclusivos. A laparotomia exploratória revelou que a cavidade abdominal estava repleta de líquido serossanguinolento e de múltiplos nódulos de diferentes tamanhos, com superfície irregular, aderidos aos peritônios visceral e parietal, sugestivos de neoplasia maligna. A eutanásia, seguida da necropsia para a coleta de amostras para o diagnóstico histopatológico, foi indicada. O exame anatomopatológico revelou nódulos sésseis e resistentes ao corte, constituídos de tecido conjuntivo fibroso e trabéculas ósseas em arranjo de osso esponjoso e osteoclastos em atividade. O diagnóstico definitivo foi peritonite encapsulante esclerosante.

Palavras-chave: cão, histopatologia, peritonite, fluido serossanguinolento

\begin{abstract}
A 5-year-old dog with chronic ascites was submitted to several clinical exams, which were inconclusive. Laparotomy revealed abdominal serosanguinous fluid and multiple nodules of several sizes with irregular surface, with visceral and parietal adhesion to the peritoneum, resembling malignant neoplasia. Euthanasia followed by necropsy and collection of samples to histopathological diagnosis was performed. Pathological exam revealed sessile nodules resistant to cut and the microscopy evaluation showed fibrous connective tissue and trabecular bone with sponge bone arrangement associated with active osteoclasts. The definitive diagnosis was sclerosing encapsulating peritonitis.
\end{abstract}

Keywords: dog, histopathology, peritonitis, serosanguinous fluid

\section{INTRODUÇÃO}

A peritonite encapsulante esclerosante é uma patologia rara entre os cães (Adamama-Moraitou et al., 2004). Em humanos consiste em séria complicação da diálise peritoneal, com morbidade e mortalidade altas (Tsai Pai et al., 2011) em nefropatas. A etiologia, ainda obscura, mas asséptica (Jubb et al., 1993), é multifatorial, incluindo-se esteatite, ingestão de fibra de vidro, complicação asséptica de infecção bacteriana (Hardie et al., 1994), sequela de diálise peritoneal (Rigby e Hawley, 1998) ou idiopática (Adamama-Moraitou et al., 2004). O quadro clínico está associado a vômitos, desconforto abdominal, massas abdominais palpáveis, ascite com líquido rico em hemácias, macrófagos e células inflamatórias. Há reação mesotelial e fibroplasia (Hardie et al., 1994), com cultura negativa para fungos e bactérias. O diagnóstico, em geral, ocorre após a laparotomia exploratória (Rigby e Hawley, 1998; Adamama-Moraitou et al., 2004); ou a necropsia (Okada et al., 2002; Adamama-Moraitou et al., 2004), mas, em humanos, o uso da tomografia computadorizada e ultrassonografia, indicados como suporte, tem permitido o diagnóstico (Campebl et al., 1994). A abertura da cavidade abdominal revela superfície peritoneal coberta por múltiplas massas de tecido de granulação (Hardie et al., 1994) e fibrose com aderências das vísceras (Dobbie, 1992; Hardie et al., 1994; Adamama-

Recebido em 9 de dezembro de 2016

Aceito em 19 de janeiro de 2017

E-mail: alessa.siqueira@gmail.com 
Moraitou et al., 2004). Microscopicamente, um agente irritativo induz uma serosite, com perda do mesotélio e fibroneogênese do peritônio (Dobbie, 1992). Não há exsudação de células inflamatórias na superfície do tecido de granulação que se encontra em várias fases de maturação (Jubb et al., 1993). A calcificação pode estar presente (Cox et al., 1992; Rigby e Hawley, 1998) e, ainda, associada à ossificação (Okada et al., 2002).

\section{CASUÍSTICA}

Um cão $\mathrm{SRD}$, com cinco anos e histórico de ascite de evolução lenta com estruturas palpáveis foi submetido à cirurgia de laparotomia exploratória por suspeita de neoplasia. A cavidade abdominal estava repleta de líquido serossanguinolento (Fig. 1).

A inspeção peritoneal revelou grave comprometimento difuso dos folhetos parietal e visceral do peritônio, com proliferações (nodulações) sugestivas de lesões neoplásicas malignas generalizadas (Fig. 2). A eutanásia e a necropsia foram indicadas. À avaliação macroscópica, notou-se, nos peritônios parietal e víscero-visceral, aderência generalizada de múltiplas formações nodosas, sésseis e de dimensões variadas $(0,5$ a $10 \mathrm{~cm})$, de consistência dura, resistentes ao corte e com superfície irregular; as maiores lembravam "almôndegas". Estas recobriam os peritônios, não se interpunham entre vísceras e mesentério, e também não penetravam no parênquima dos órgãos (Fig. 3). As maiores formações se localizavam no diafragma. $\mathrm{E}$ a face diafragmática do fígado estava recoberta em quase sua totalidade, mas não havia invasão para o parênquima, e os nodos coalescentes podiam ser removidos, deixando livre a superfície do órgão. Com certa pressão, os nodos maiores podiam ser destacados da superfície onde se fixavam e, por vezes, a porção central da base drenava um líquido sanguinolento, deixando livre e quase intacta uma superfície umbilicada. Ao corte, as formações eram excessivamente consistentes, compatíveis com deposição de minerais. A cavidade torácica estava preservada (Fig.4).
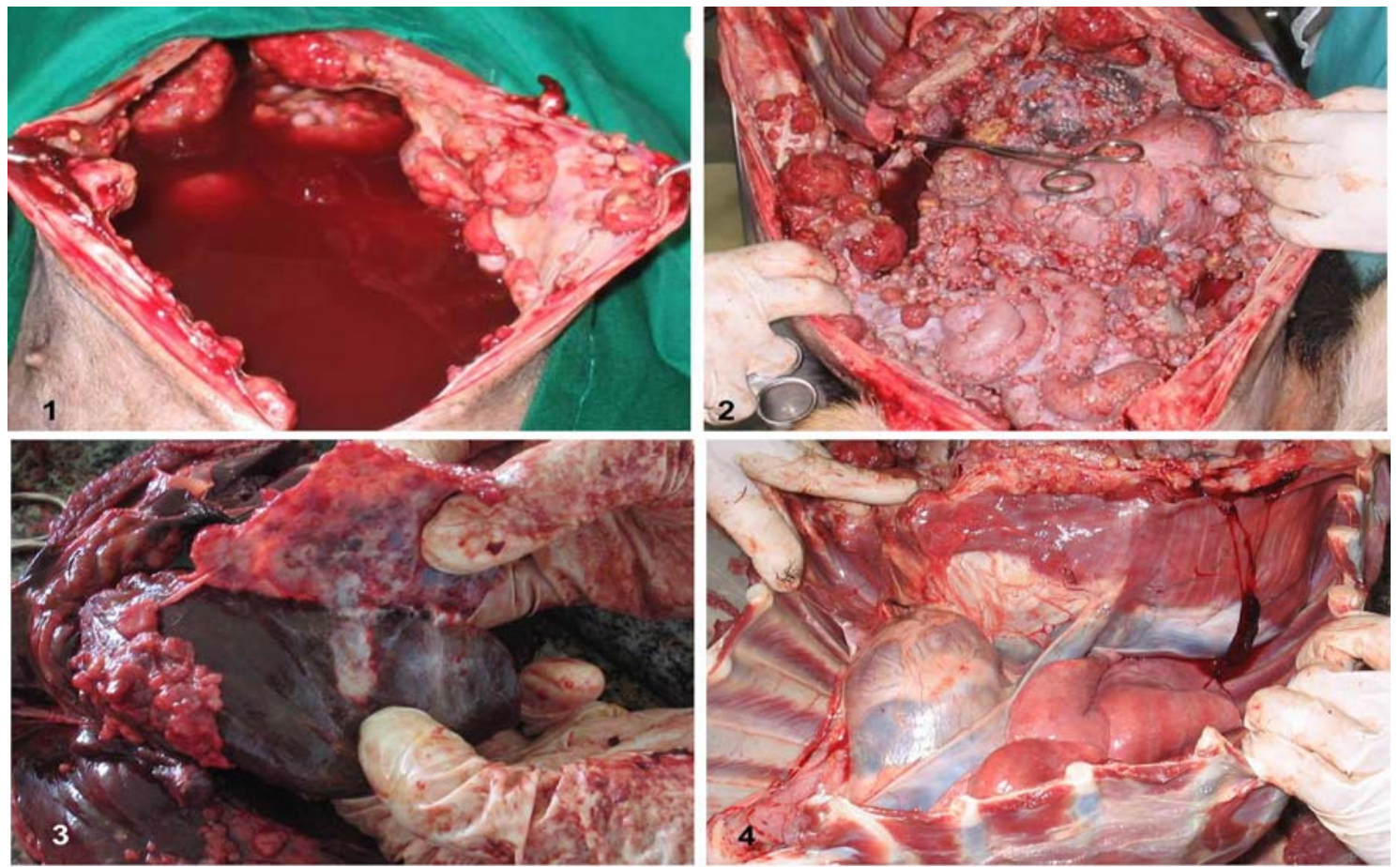

Figuras. 1-4. Peritonite encapsulante esclerosante. Cavidade abdominal. Cão. Figura. 1. Líquido ascítico serossanguinolento. Figura. 2. Múltiplas formações nodosas, sésseis e de dimensões variadas, de consistência dura, resistentes ao corte e de superfície irregular. Figura. 3. Múltiplas formações nodosas recobrindo os peritônios, mas que não penetravam no parênquima dos órgãos. Figura. 4. Cavidade torácica preservada, sem lesões. 
Estes achados caracterizaram a peritonite encapsulante esclerosante (PEE), que, apesar de exuberante, múltipla e difusa, não invade o parênquima de vísceras (Dobbie, 1992; Hardie et al., 1994; Okada et al., 2002; AdamamaMoraitou et al., 2004). Amostras das lesões nodosas, aderências e vísceras foram coletadas e fixadas em formalina neutra tamponada a $10 \%$, processadas por inclusão em parafina e coradas pela hematoxilina e eosina (HE). A microscopia dos nodos de tecido conjuntivo fibroso, de variados tamanhos, revelou trabéculas ósseas em arranjo de osso esponjoso com disposição radiada da superfície para a base (Fig. 5). Espículas ósseas estavam imersas em medula mielogênica (Fig. 6) e osteoclastos em atividade (Fig. 7).
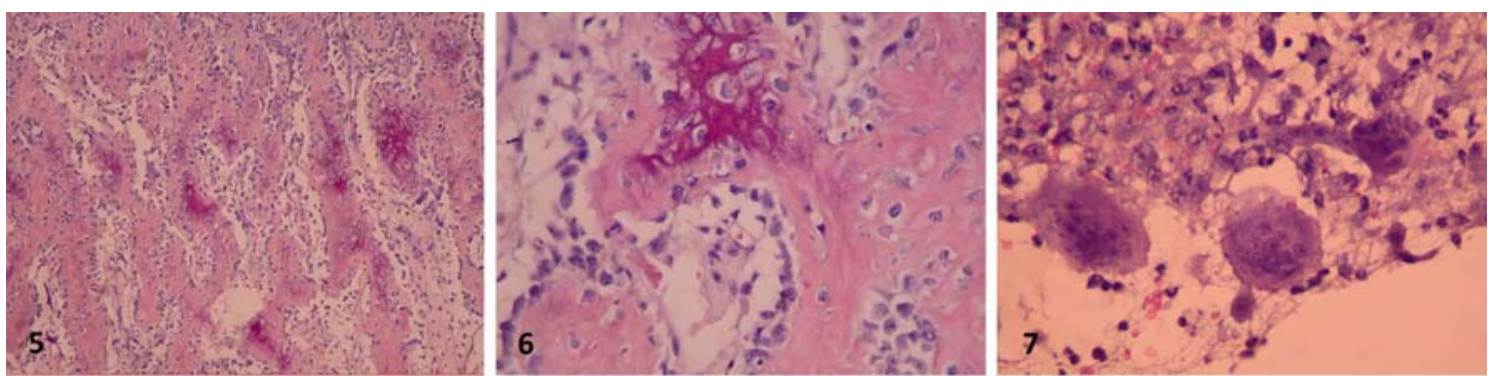

Figuras. 5-7. Peritonite encapsulante esclerosante. Fotomicrografia de lesão nodosa. Cão. Figura. 5. Trabéculas ósseas em arranjo de osso esponjoso com disposição radiada da superfície para a base. HE (x 100). Figura. 6. Osso esponjoso com medula óssea mielogênica. HE (x 200) Figura. 7. Osteoclastos em atividade. HE (x 400).

\section{DISCUSSÃO E CONCLUSÕES}

Em geral, a microscopia da lesão de PEE se constitui em tecido conjuntivo laminar fibroso (Jubb et al., 1993; Hardie et al., 1994; Adamama-Moraitou et al., 2004), podendo haver focos de calcificação (Cox et al., 1992; Okada et al., 2002). O processo de calcificação associado à ossificação já foi descrito na PEE em humanos (Cox et al., 1992; Okada et al., 2002; Tsai Pai et al., 2011). Nestes, essa calcificação é decorrente de vários anos de diálise peritoneal ambulatorial contínua (Tsai Pai et al., 2011).

No entanto, as causas da PEE, como diálise peritoneal em humanos (Tsai Pai et al., 2011) ou sequela de infecção bacteriana em cães (Hardie et al., 1994), nem sempre podem ser apuradas. O diagnóstico de PEE ossificante associada à ascite serossanguinolenta de causa idiopática em cão consiste no primeiro registro da enfermidade na literatura disponível.

\section{REFERÊNCIAS}

ADAMAMA-MORAITOU, K.K.; PRASSINOS, N.N.; PATSILKAS, M.N. et al. Sclerosing encapsulating peritonitis in a dog with leishmaniasis. $J$. Small Anim. Pract., v.45, p.117-121, 2004.
CAMPEBL, S.; CLARK, P.; HAWLEY, C. et al. Sclerosing peritonitis: Identification of diagnostic, clinical and radiological features. Am. J. Kidney Dis., v.24, p.819-825, 1994.

COX, S.V.; LAI, J.; SURANYI, M. et al. Sclerosing peritonitis with gross peritoneal calcification: a case report. Am. J. Kidney Dis., v.20, p.637-642, 1992.

DOBBIE, J.W. Pathogenesis of peritoneal fibrosing syndromes (sclerosing peritonitis) in peritoneal dialysis. Perit. Dial. Int., v.12, p.14-27, 1992.

HARDIE, E.M.; ROTTMAN, J.B.; LEVY, J.K. Sclerosing encapsulating peritonitis in four dogs and a cat. Vet. Surg., v.23, p.107-114, 1994.

JUBB, K.V.; KENNEDY, P.C.; PALMER, N. Pathology of domestic animals. [Cambridge]: Academic Press, 1993. [653p.].

OKADA, K.; ONISHI, Y.; OINUMA, T. et al. Sclerosing encapsulating peritonitis: regional changes of peritoneum. Nephron, v.92, p.481-483, 2002.

RIGBY, R.J.; HAWLEY, C.M. Sclerosing peritonitis: the experience in Australia. Nefphrol. Dial. Transplant., v.13, p.154-159, 1998.

TSAI PAI, M.A.; YU, J.K.; YU, Y.L. et al. Sclerosing encapsulating peritonitis in a case on continuous cyclic peritoneal dialysis. Acta Nephrol., v.25, p.77-80, 2011. 